\title{
Descrição anátomo-topográfica do coração da paca (Agouti paca)
}

\author{
Anatomotopographic description of the paca heart (Agouti paca) \\ Bruna Helena Pinheiro Ávila', Márcia Rita Fernandes Machado' \& Fabrício Singaretti de Oliveira ${ }^{2}$
}

\begin{abstract}
Background: The domestic animals heart is a conical hollow viscera, surrounded by pericardium, laterally compressed, accompanying the thorax shape. Atriums constituted the heart basis and their auricles partially bound the initial portion of the aorta and pulmonary trunk. In mammals, heart is kept suspended in the thoracic cavity and the pericardic sac is fixed dorsally by great veins and arteries roots, and ventrally fixed to the sternum, although its fixation to the diaphragm varies among species. This paper aimed to describe morphological aspects of the heart of the paca, the second biggest Brazilian rodent.

Materials, Methods \& Results: There were used 12 hearts of adult pacas for this study, obtained from the UNESP, Jaboticabal, $\mathrm{SP}$, which died due fights or anesthesia during bandages or radiograph exams. The thoracic aorta was filled with colored latex and the animal was set in a 10\% formaldehyde solution for at least 72 hours. The thoracic cavity was dissected and hearts individualized and measured with a paquimeter, lateromedially, craniocaudally and dorsoventrally. The paca heart is placed between the first and fifth intercostal space (ICS), in a craniocaudal oblique position; its basis is craniodorsally positioned, on the middle third between the first and second ICS and its apex is located near the sternodiaphragmatic joint, on the fifth ICS, tilted to the left antimere. The heart is surrounded by pericardium, which from ventrocaudally is originated the sternopericardic ligament, that continues as phrenopericardic ligament. At the heart basis, the rising of the pulmonary trunk was observed and the conus arteriosus formed a typical projection. The aorta also rised from the heart basis and its arch, which was caudally curved, crossed dorsally the pulmonary trunk; the right cranial and caudal cava veins drained to the right atrium. There is a left cranial cava vein, which surrounded the left atrium and joined the right caudal cava vein on the right atrium. The azygos vein joins the right cranial cava vein and four pulmonary veins drained to the left atrium. At palpation, a hard structure on the rising of the aorta was observed, similarly to a cartilaginous tissue, which would be part of the cardiac skeleton. The left and right coronary arteries were observed in all hearts.

Discussion: The paca heart is anatomica and topographically similar to those of domestic mammals, differing from them for being placed one intercostal space more cranial and due to the presence of two cranial cava veins, the left and the right ones, besides the presence of the caudal cava vein. This vascular description is similar to that of small rodents, as rats and mice. In paca heart, the sinus venous, the terminal crest, the oval fossa, the atrioventricular valvae, the papillary muscles and tendinous cords, besides smooth atriums and auricles covered by pectinate muscles, were observed. The sternopericardic ligament, which is dorsally elongated as phrenopericardic ligament, is similar to the one present in humans, pigs, castors, and different from the one observed in carnivorous, that presents the phrenopericardic ligament and from the one of horses and ruminants, which present the sternopericardic ligament.
\end{abstract}

Keywords: anatomy, heart, Agouti paca.

Descritores: anatomia, coração, Agouti paca. 


\section{INTRODUÇÃO}

O coração dos animais domésticos é um órgão oco, envolvido pelo pericárdio, cônico e comprimido látero-lateralmente, acompanhando a forma do tórax. Constitui-se de quatro câmaras, dois átrios e dois ventrículos, direitos e esquerdos, separados pelos septos. Os átrios constituem a base do coração e suas aurículas contornam parcialmente a parte inicial da aorta e do tronco pulmonar. Na face esquerda, são visíveis as duas aurículas, o tronco pulmonar e a aorta. Na direita, evidenciam-se as veias cavas cranial e caudal [2-4,9,12].

Nos mamíferos, o coração fica suspenso na cavidade torácica, e o saco pericárdico é fixo, dorsalmente, pela raiz das grandes artérias e veias e, ventralmente, preso ao esterno, embora sua fixação ao diafragma varie entre as espécies. No homem, suínos e castor, a ligação do pericárdio à porção tendínea do diafragma é firme e larga; nos carnívoros, um ligamento ventral é a única união entre o pericárdio e diafragma e nos equinos e ruminantes, a porção caudal do pericárdio era fixada apenas através do ligamento esternopericárdico [8].

Nos ratos [6] e nos camundongos, [1] há um ventrículo direito e um esquerdo, além de átrios direito e esquerdo, facilmente distinguíveis. Desembocam no átrio direito a veia cava cranial direita, a veia cava cranial esquerda e a veia cava caudal. A veia cava caudal desemboca no átrio direito, juntamente com as veias cavas craniais esquerda e direita.

Este trabalho objetivou descrever aspectos morfológicos do coração da paca, o segundo maior roedor brasileiro.

\section{MATERIAIS E MÉTODOS}

Foram utilizados doze corações de pacas adultas, seis machos e seis fêmeas, provenientes do Setor de Animais Selvagens da Faculdade de Ciências Agrárias e Veterinárias, UNESP, Jaboticabal, SP, as quais vieram a óbito devido a brigas ou à anestesia para realização de curativos ou radiografias, não comprometendo o estudo conduzido.

Mediante incisão com bisturi, foi realizada abertura lateral da cavidade torácica, no sexto espaço intercostal esquerdo, para identificação da aorta torácica, a qual foi canulada e injetada com látex pigmentado com corante vermelho ${ }^{1}$. A seguir, o animal foi congelado a $-10^{\circ} \mathrm{C}$ por 48 horas para endure- cimento do látex e descongelado, então, para fixação mediante injeção intramuscular de solução aquosa de formaldeído a $38 \%$.

Todas as peças anatômicas foram conservadas na mesma solução, mas a $10 \%$, até a dissecação. A cavidade torácica foi dissecada para a observação da topografia cardíaca e, em sequência, os corações foram individualizados e medidos, com auxílio de paquímetro, lateralmente, e entre as margens caudal e cranial e as extremidades dorsal (cone arterioso) e ventral (ápice cardíaco) (Tabela 1). Os termos utilizados nesse artigo estão de acordo com a Nomenclatura Anatômica Veterinária [11].

\section{RESULTADOS}

Em todas as preparações examinadas, observou-se que o coração da paca está localizado entre o primeiro e quinto espaços intercostais, em posição oblíqua craniocaudal; a base cardíaca posiciona-se craniodorsalmente, na altura do terço médio entre o primeiro e segundo espaços intercostais e o ápice localiza-se próximo à junção esternodiafragmática,

Tabela 1. Dimensões, no sentido dorso-lateral (DL), crânio-caudal (CC) e látero-lateral (LL), em centímetros $(\mathrm{cm})$, do coração de pacas adultas, com média e desvio padrão (DP).

\begin{tabular}{cccc}
\hline coraçães & DL & CC & LL \\
\hline coração 1 & 5,52 & 4,00 & 3,30 \\
coração 2 & 5,00 & 3,50 & 3,00 \\
coração 3 & 5,30 & 4,20 & 3,30 \\
coração 4 & 5,40 & 4,00 & 3,20 \\
coração 5 & 4,50 & 3,20 & 2,50 \\
coração 6 & 4,50 & 3,00 & 2,20 \\
coração 7 & 4,50 & 3,50 & 2,00 \\
coração 8 & 4,60 & 3,90 & 2,40 \\
coração 9 & 5,00 & 3,50 & 2,70 \\
coração 10 & 5,00 & 3,20 & 2,80 \\
coração 11 & 4,80 & 3,20 & 2,00 \\
coração 12 & 4,90 & 3,70 & 2,00 \\
\hline Média & 4,92 & 3,58 & 2,66 \\
DP & 0,36 & 0,39 & 0,47 \\
\hline
\end{tabular}


no quinto espaço intercostal, voltado para o antímero esquerdo (Figura 1).

O coração da paca está envolto pelo pericárdio, do qual, ventrocaudalmente, origina-se o ligamento esterno-pericárdico, que se prolonga dorsalmente como ligamento frênico-pericárdico. O coração da paca apresenta a forma de cone alongado, constituído por dois átrios e dois ventrículos, direitos e esquerdos. Possui um estreitamento na junção entre as aurículas e os átrios, mais evidente entre a aurícula e o átrio esquerdo e as margens auriculares são pouco recortadas (Figura 2).

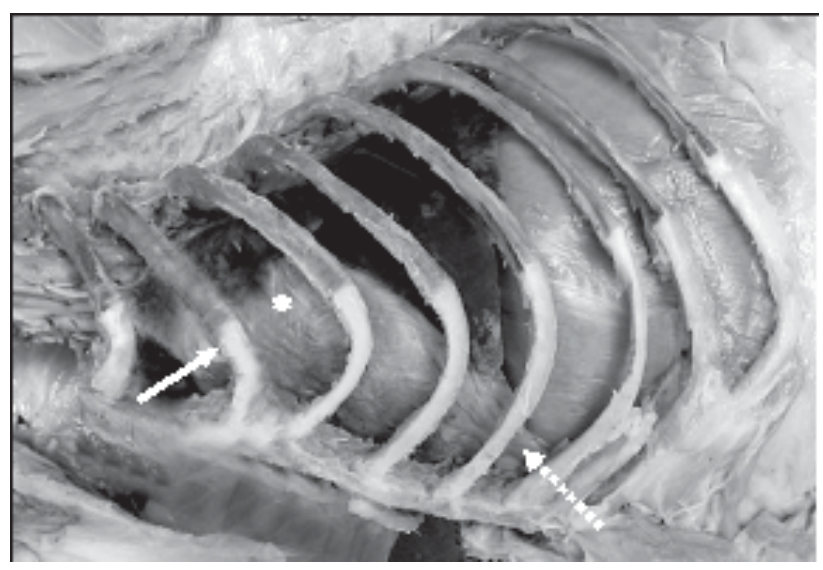

Figura 1. Fotografia da caixa torácica de uma paca adulta, mostrando o coração localizado entre o primeiro e quinto espaços intercostais (seta contínua e seta tracejada, respectivamente), em posição oblíqua; a base cardíaca (*) está posicionada craniodorsalmente e o ápice, próximo à junção do esterno ao diafragma, no quinto espaço intercostal.
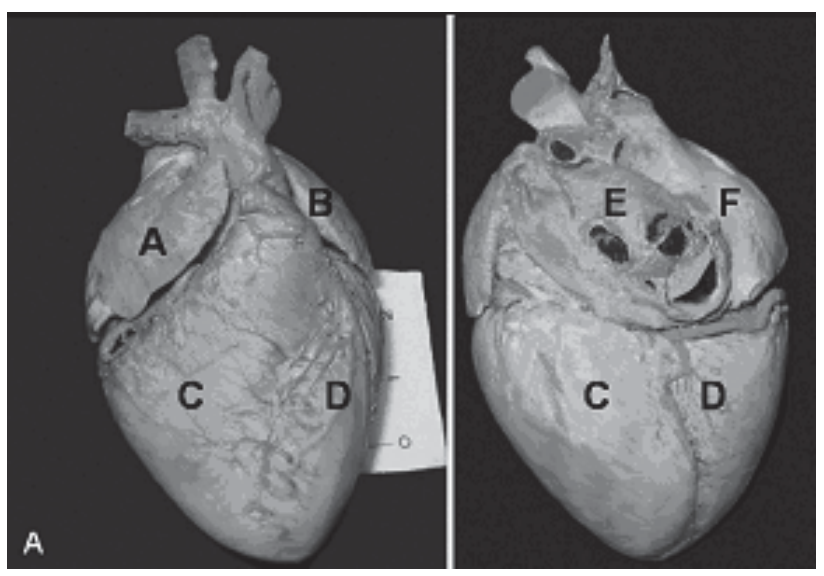

Figura 2. Coração de paca adulta e seu formato piramidal. A: Face esquerda na qual se identificam as aurículas direita (A) e esquerda (B) e ventrículos direito (C) e esquerdo (D). B: Face direita, na qual se pode identificar os átrios esquerdo (E) e direito $(\mathrm{F})$, além dos ventrículos direito $(\mathrm{C})$ e esquerdo (D).
Na base do coração, observou-se a emergência do tronco pulmonar e o cone arterioso formava uma projeção característica. Também se originava a aorta e seu arco voltava-se caudalmente cruzando dorsalmente o tronco pulmonar; no átrio direito desembocam as veias cavas cranial direita e a veia cava caudal. Observou-se a presença da veia cava cranial esquerda, a qual contornava o átrio esquerdo e encontrava-se com a veia cava caudal direita, na altura da desembocadura desta no átrio direito. A veia ázigos desembocava na veia cava cranial direita e quatro veias pulmonares adentravam no átrio esquerdo.

Internamente, o coração apresentava os átrios direito e esquerdo lisos, embora as aurículas estivessem revestidas por músculos pectiniformes bastante recortados. O seio venoso, a crista terminal, a fossa oval e as valvas átrioventriculares direita e esquerda também estavam presentes.

Nas paredes ventriculares, além dos músculos papilares, aos quais as cordas tendíneas estavam fixadas, foram observados arranjos trabeculares desses músculos. No ventrículo direito, notou-se uma faixa muscular alongada e bifurcada, que se estendia do septo interventricular à parede do referido ventrículo, similarmente à trabécula septo-marginal; no ventrículo esquerdo, além do arranjo trabecular, foram evidenciados dois músculos papilares característicos.

Observou-se ainda, à palpação, uma estrutura rija na emergência da aorta, semelhante a tecido cartilaginoso, a qual estaria compondo o esqueleto cardíaco.

Os valores médios das medidas da distância dorso-ventral, da distância crânio-caudal e látero-lateral do coração de uma paca adulta são expostos na Tabela 1.

Em todos os corações analisados, foi observada a presença das artérias coronária esquerda e direita.

\section{DISCUSSÃO}

O coração da paca, assim como o dos animais domésticos [2-4,7,9,12], e mamíferos de modo geral [8], apresenta-se localizado na cavidade torácica, em posição oblíqua crânio-caudal. O mesmo situa-se entre o primeiro e quinto espaços intercostais, diferentemente dos animais domésticos [2$4,7,9,12]$, os quais apresentam o coração do segundo ao quinto espaços intercostais. 
Semelhante ao coração dos animais domésticos, selvagens e de laboratório, o coração da paca apresenta seio venoso, crista terminal, fossa oval, valvas atrioventriculares, músculos papilares e cordas tendíneas característicos, além de átrios lisos e aurículas revestidas por músculos pectiniformes bastante recortados. No ventrículo direito, notou-se uma faixa muscular alongada e bifurcada, que se estendia do septo interventricular à parede do referido ventrículo, similarmente à trabécula septo-marginal dos animais domésticos [2,4,7].

Há o ligamento esterno-pericárdico, o qual se prolonga dorsalmente como ligamento frênicopericárdico, semelhante ao que ocorre no homem, suíno e castor [8] e diferentemente do carnívoro, que apresenta apenas o ligamento frênico-pericárdico e do equino e ruminante, nos quais se evidencia apenas o ligamento esterno-pericárdico $[2,4,12]$.

O coração da paca tem a forma de um cone alongado e é constituído por dois átrios e dois ventrículos (direitos e esquerdos), como nos animais domésticos $[2,4,7,12]$, animais de laboratório, selvagens terrestres e mamíferos aquáticos [8], no rato [6] e no camundongo [1].

No átrio direito do coração da paca, desembocam a veia cava cranial direita e a veia cava caudal; a veia cava cranial esquerda encontra-se próximo à desembocadura da cranial direita no referido átrio, diferentemente do observado em animais domésticos $[2-4,7,9,12]$ e na cutia, o terceiro maior roedor brasileiro, os quais apresentam apenas as veias cavas cranial e caudal [10]. Esta descrição é, entretanto, semelhante ao reportado nos ratos, que possuem duas veias cavas craniais (esquerda e direita) e uma caudal [5].

No átrio esquerdo do coração da paca, desembocam quatro veias pulmonares; a veia ázigos drena para a veia cava cranial direita, diferentemente do observado no rato de laboratório, no qual a veia ázigos desemboca na veia cava cranial esquerda [5].

Foi observada, em todos os corações analisados, a presença das artérias coronária esquerda e direita se originando diretamente da aorta, como ocorre nos animais domésticos [2,4,7].

O coração da paca é anatômica e topograficamente similar àquele dos mamíferos domésticos, diferindo por localizar-se em um espaço intercostal mais cranial e por apresentar duas veias cavas craniais, a esquerda e a direita, além da veia cava caudal. Entretanto, essa descrição vascular é semelhante àquela de pequenos roedores, como ratos e camundongos.

\section{NOTAS INFORMATIVAS}

${ }^{1}$ Corante Xadrez ${ }^{\circledR}$ - Sherwin Williams S.A., Taboão da Serra, SP, Brasil

\section{REFERÊNCIAS}

1 Ciszek B., Skubiszewska D. \& Ratajska A. 2007. The anatomy of the cardiac veins in mice. Journal of Anatomy. 211(1): 5363.

2 Dyce K.M., Sack W.O. \& Wensing C.J.G. 2004. Tratado de Anatomia Veterinária. 2.ed. Rio de Janeiro: Elsevier, pp. 215229.

3 Frandson R.D., Wilke W.L. \& Fails A.D. 2005. Anatomia e Fisiologia dos Animais de Fazenda. 6. ed. Rio de Janeiro: Guanabara Koogan, pp. 250-265.

4 Ghoshal N.G. 1986. Coração e artérias. In: Sisson S \& Grossman J.D. (Eds). Anatomia dos Animais Domésticos. V.1. 5.ed. Rio de Janeiro: Guanabara Koogan, pp. 518-527; 900-958; 1497-1550.

5 Halpern M.H. 1953. The azygos vein system in the rat. The Anatomical Record. 116(1): 83-93.

6 Hebel R. \& Stromberg M.W. 1986. Anatomy and Embryology of the Laboratory Rat. Wörthsee: BioMed Verlag, 270p.

7 König H.E. \& Liebich H.G. 2004. Órgãos do sistema cardiovascular. In: Anatomia dos Animais Domésticos. v.2. Porto Alegre: Artmed, pp. 153-188.

8 Michaelsson M. \& Ho S.Y. 2000. Congenital Heart Malformations in Mammals: an Illustrated Text. London: Imperial College Press, pp. 132-134.

9 Nickel R., Schummer A. \& Seiferle E. 1981. The Anatomy of the Domestic Animals. Berlin: Verlag Paul Parey, pp.159-175. 10 Oliveira P.F.N., Carvalho M.A.M., Souza W.M. \& Miglino M.A. 1999. The right azygos vein in agouti (Dasyprocta agouti, rodentia). Brazilian Journal of Veterinary Research and Animal Science. 36:4. Disponível em http://www.scielo.br/ scielo.php?script=sci_arttext\&pid=S1413-95961999000400002\&lng=en\&nrm=iso. 
11 Schaller O. 1999. Nomenclatura Anatômica Veterinária Ilustrada. São Paulo: Manole, 614p.

12 Schwarze E. \& Schröder L. 1972. Compêndio de Anatomia Veterinária. Zaragoza: Acribia, 247p. 
